\title{
Carbazole based electrochromic polymers with benzoazole units: Effect of heteroatom variation on electrochromic performance
}

\author{
C. Doyranli ${ }^{1,2}$, F. Baycan Koyuncu ${ }^{1,2 *}$ \\ ${ }^{1}$ Department of Chemistry, Faculty of Sciences and Arts, Çanakkale Onsekiz Mart University, 17020 Çanakkale, Turkey \\ ${ }^{2}$ Polymeric Materials Research Laboratory, Çanakkale Onsekiz Mart University, 17020 Çanakkale, Turkey
}

\begin{abstract}
A series of carbazole-based polymers were synthesized via Suzuki polymerization between N-(2-ethylhexyl)carbazole-3,6-bis(ethyleneboronate) (Cbz) and dibromobenzazole unit. Three different polymers, PCBN, PCBS and PCBSe were obtained from 4,7-dibromo-2-hexyl-2H-benzotriazole (BN), 4,7-dibromo-2,1,3-benzothiadiazole- (BS) and 4,7-dibromo-2,1,3-benzoselenadiazole (BSe), respectively. It is observed that, the variation of heteroatoms (N,S and Se) on the benzazole unit have most important effect on electro-optic properties of the PCBX polymers. Neutral state color of the polymer films and their electrochromic performances are also influenced. Among the synthesized polymers, the PCBS bearing 2,1,3benzothiadiazole as acceptor units has a broad absorption and $50 \%$ of $\Delta T$ in the near-IR regime at the oxidized state. This property of PCBS is a great advantage for near-IR electrochromic applications.
\end{abstract}

Keywords: polymer synthesis, molecular engineering, electrochromic polymers, carbazole, benzotriazole, benzothiadiazole

\section{Introduction}

For 20 years, the donor-acceptor electrochromic polymers have been intensively studied owing to their respectable properties such as their tunable band gaps, and also electrochemical and optical properties. A reversible and visual color change called as electrochromism is obtained by the reversible redox behavior of the electroactive polymers. Electron-donor and electron-withdrawing parts are attached on the same polymer backbone of the donor-acceptor systems [1]. HOMO-LUMO energy levels of these systems are recognized exactly due to their dual electrochemical properties. These polymers have also an important charge transfer band in the neutral state to apply on the photovoltaic and electroluminescent devices. They also can be used in electrochromic materials to fabricate smart windows $[2,3]$, switchable mirrors $[4,5]$ and camouflage materials $[6,7]$.
Carbazole is one of the widely used donor moieties in the donor-acceptor systems as it can be functionalized at different positions such as $(3,6)[8],(2,7)[9]$ or N-positions [10]. It is also an efficient blue emissive polymer in the organic light emitting diodes [11]. Owing to their effective carrier transport properties, carbazole based polymers can form relatively stable cations (polarons) and dications (bipolarons) when applying positive potential or doping agent [12]. Because of these superior properties, these polymers can be used in electrochromic materials, light emitting diodes, electrophotography and as photovoltaic constituents [9, 13-15]. Nevertheless, organic optoelectronic applications of poly-3,6-carbazoles are limited because of both poor conjugation within the polymer backbone and also not obtaining high molecular weights. Therefore, poly-3,6-carbazoles are still used as host materials because of 
their high ability of hole transporting [16-18]. Besides, these polymers demonstrate remarkable electrochromic properties due to the conjugation broken on the carbazyl nitrogen. One of the exciting multicolor polymer frameworks based on the 3,6-linked carbazole moiety was proposed by Reynolds and coworkers [18-20]. These polymers can form radical cations that are separated from each other owing to the broken conjugation on the polymer backbone. When applying higher potentials on the polymer, radical dications (bipolarons) are formed in the polymer system via removing another electron. For these reasons, electrochromic materials containing poly $(3,6)$ carbazole derivatives have multielectrochromic behavior due to their district oxidation property in the anodic regime [21, 22].

To understand the effect of heteroatom variation both on electro-optic properties of polymers and also on their electrochromic performance, we synthesized a series of donor-acceptor polymers based on N-(2-ethylhexyl)carbazole-3,6-bis(ethyleneboronate) (Cbz) and dibromobenzazole unit (BX)with different heteroatoms (N, S and Se) named as poly(4,7-(N-hexylbenzotriazole)-3,6-(N-(2-ethylhexyl)carbazole) (PCBN), poly(4,7-(2,1,3-benzothiadiazole)-3,6-(N(2-ethylhexyl)carbazole) (PCBS) and poly(4,7-(2,1,3benzoselenadiazole)-3,6-(N-(2-ethylhexyl)carbazole) (PCBSe). The band gap of polymers and also the neutral state color of the films can be tuned by attaching a heteroatom on the acceptor moiety, changing nitrogen to sulfur or selenium. Further, owing to multi step redox behavior at the anodic regime, various colors were obtained on the polymer films upon applied potentials. Among the PCBX polymers, PCBS has a broad absorption and $50 \%$ of $\Delta T$ in the near-IR regime at the oxidized state. Owing to this property, PCBS can be a good candidate to use for near-IR electrochromic applications.

\section{Experimental section \\ 2.1. Materials}

Compounds were procured from Aldrich. The initial compounds (Cbz, BN, BS and BSe) were prepared and characterized according to the literature [23].

\subsection{Instrumentation}

Fourier transform infrared spectra (FT-IR) were recorded on a Perkin Elmer FT-IR Spectrum One spec- trometer by using an attenuated total reflectance (ATR) module (4000-650 $\left.\mathrm{cm}^{-1}\right) .{ }^{1} \mathrm{H}-\mathrm{NMR}$ spectra were recorded on a Bruker Advance DPX-400 at $25^{\circ} \mathrm{C}$ in deuterated chloroform solutions with tetramethylsilane (TMS) as internal standard. Electrochemical analyses were performed by Biologic SP50 potentiostat-galvanostat system with a platinum disk $\left(0.02 \mathrm{~cm}^{2}\right)$ as working electrode (WE), Ag wire as reference electrode (RE) and Pt wire as counter electrode (CE). UV-vis absorption spectra were recorded by an Analytic Jena Speedcord S-600 diode-array spectrophotometer. The optical band gaps $\left(E_{\mathrm{g}}\right)$ of polymers were found from their absorption onsets [24]. The emission spectra measurements were taken by a PTI QM1 fluorescence spectrophotometer. Spectroelectrochemical measurements were carried out to consider absorption spectra of polymer films under applied potential. The color coordinates are determined by three characteristics; luminance (L), hue (a), and saturation (b) in Commission Internationale de 1'Elcairage (CIE) system [25]. To determine these characteristics, Analytic Jena UV-vis spectrophotometer containing a chromameter module was used. GPC analysis of the polymers was performed with Agilent 1260 HPLC instrument. This system consists of an Agilent 1200 series pump, three Waters Styragel HR columns (guard, 4, 3) and a BI-DNDC differential refractometer (Brookhaven Instruments Corporation, $620 \mathrm{~nm}$ ) with a THF flow rate of $1 \mathrm{~mL} / \mathrm{min}$. Polystyrene was used as calibration standard. Surface morphologies were investigated by Nanosurf Naio AFM.

\subsection{Synthesis of PCBX polymers}

The polymers were synthesized via Suzuki polymerization reaction between 2-ethylhexyl-9H-carbazole3,6-diboronicacidbis(1,3-propanediole) ester and dibromo benzoazole-based heterocycles. Benzoazoledibromide (1 mol) and 2-ethylhexyl-9H-carbazole3,6-diboronic acid bis(1,3-propanediole) ester (1 mol) were added into potassium carbonate solution $\left(\mathrm{K}_{2} \mathrm{CO}_{3}\right.$, $2 \mathrm{M}$ in $\left.\mathrm{H}_{2} \mathrm{O}\right)$ and $20 \mathrm{~mL}$ toluene. Then, $\mathrm{Pd}\left(\mathrm{PPh}_{3}\right)_{4}$ ( $5 \mathrm{~mol} \%$ ) was added to flask. The mixture was heated to $110^{\circ} \mathrm{C}$ and refluxed for $16 \mathrm{~h}$ under $\mathrm{N}_{2}$. For ending the reaction benzeneboronic acid $(0.122 \mathrm{~mol})$ was added and refluxed about $3 \mathrm{~h}$ and then bromobenzene $(0.122 \mathrm{~mol})$ was also put into flask and stirred for $3 \mathrm{~h}$, too. Lastly, the mixture was cooled and then 
filtered. After that, it poured into methyl alcohol. The crude product was filtered again and dried. Soxhlet extraction was achieved with methyl alcohol and then $\mathrm{CHCl}_{3}$ for the last purification.

PCBN (Yield 78\%; yellow powder): FTIR $\left[\mathrm{cm}^{-1}\right]$ : 3094 (C-H aromatic); 2957, 2931, $2856(C-H$ aliphatic); $1615(C=N) ; 1595,1530(C=C$ aromatic $)$; $1443(\mathrm{C}-\mathrm{N}) ;{ }^{1} \mathrm{H}-\mathrm{NMR}\left(\mathrm{CHCl}_{3}-d\right): \delta \mathrm{ppm}, 8.84-7.17$ ( $m, 8 \mathrm{H}, \mathrm{C}-\mathrm{H}$ aromatic); 4.81 ( $\mathrm{m}, 2 \mathrm{H},-\mathrm{NCH}_{2}-$, triazole); 4.52 ( $\mathrm{m}, 2 \mathrm{H},-\mathrm{NCH}_{2}-$, carbazole $) ; 2.17-1.33$ ( $\mathrm{m}, 17 \mathrm{H}, \mathrm{C}-\mathrm{H}$ aliphatic); $0.91\left(\mathrm{~m}, 9 \mathrm{H},-\mathrm{CH}_{3}\right)$.

PCBS (Yield 86\%; orange powder): FTIR [ $\left.\mathrm{cm}^{-1}\right]$ : 3086 ( $\mathrm{C}-\mathrm{H}$ aromatic); 2954, 2929, 2850 (C-H aliphatic); $1612(C=N) ; 1578,1524(C=C$ aromatic $)$; $1441(\mathrm{C}-\mathrm{N}) ;{ }^{1} \mathrm{H}-\mathrm{NMR}\left(\mathrm{CHCl}_{3}-d\right): \delta \mathrm{ppm}, 8.82-7.48$ ( $\mathrm{m}, 8 \mathrm{H}, \mathrm{C}-\mathrm{H}$ aromatic); $4.29\left(\mathrm{~m}, 2 \mathrm{H},-\mathrm{NCH}_{2}-\right)$; 2.19 1.38 ( $\mathrm{m}, 9 \mathrm{H}, \mathrm{C}-\mathrm{H}$ aliphatic); $0.91\left(\mathrm{~m}, 6 \mathrm{H},-\mathrm{CH}_{3}\right)$.

PCBSe (Yield 82\%; red powder): FTIR [ $\left.\mathrm{cm}^{-1}\right]$ : 3084 (C-H aromatic); 2950, 2925, 2796 ( $C-$ H aliphatic); $1610(C=N) ; 1574,1522(C=C$ aromatic $) ; 1440$ $(\mathrm{C}-\mathrm{N}) ;{ }^{1} \mathrm{H}-\mathrm{NMR}\left(\mathrm{CHCl}_{3}-\mathrm{d}\right): \delta \mathrm{ppm}, 8.71-7.16(\mathrm{~m}$, $8 \mathrm{H}, \mathrm{C}-\mathrm{H}$ aromatic); 4.29 ( $\left.\mathrm{m}, 2 \mathrm{H},-\mathrm{NCH}_{2}-\right) ; 2.15-$ 1.39 ( $m, 9 H, C-H$ aliphatic); $0.91\left(m, 6 H,-\mathrm{CH}_{3}\right)$.

\section{Results and discussion}

\subsection{Synthesis of PCBX polymers}

$\mathrm{Cbz}, \mathrm{BN}, \mathrm{BS}$ and BSe were synthesized according to procedures from the literature [23]. Syntheses of the polymers (PCBN, PCBS and PCBSe) were achieved by Suzuki reaction between Cbz-donor and BX-acceptors respectively (Figure 1). FTIR and ${ }^{1} \mathrm{H}-\mathrm{NMR}$ analysis were used to prove the formation of the PCBX polymers. Noteworthy, spectral properties variations were detected for initial and the final compounds. According to ${ }^{1} \mathrm{H}-\mathrm{NMR}$ spectra of polymers, carbazole and benzazole aromatic proton signals were observed 8.84-7.16 ppm. Because of the electron-acceptor effect of carbazyl nitrogen, $\mathrm{N}-\mathrm{CH}_{2}$ aliphatic group signal was detected at higher ppm, (4.52 ppm for PCBN - $4.29 \mathrm{ppm}$ for PCBS and PCBSe) than that of other aliphatic protons (Figure 2). The similar situation was also observed in the benzotriazole's $\mathrm{N}-\mathrm{CH}_{2}$ aliphatic signal (4.81 ppm).

GPC was used for the investigation of polydispersity index (PDI) and molecular weight of the polymers. According to GPC measurements, degree of polymerization of PCBX polymers was found to be 7, 6 and 4 respectively (Table 1). The results obtained indicate that these molecules are oligomers. Because of the presence of an alkyl chain on the benzotriazole moiety, the molecular weight of PCBN higher than that of the other polymers.

\subsection{Optical properties of PCBX polymers}

The optic characterization of $\mathbf{P C B X}$ polymers were achieved by UV-Vis and Fluorescence spectroscopy. Owing to $\pi-\pi^{*}$ transitions arising from the conjugation of the polymer main chain, PCBX polymers showed absorption bands at about $300 \mathrm{~nm}$. Besides, because of the interaction of carbazole-donor and benzazole-acceptor at the conjugated polymer system, a typical charge transport band was obtained at $360 \mathrm{~nm}$ for PCBN, at $440 \mathrm{~nm}$ for PCBS and at $475 \mathrm{~nm}$ for PCBSe, respectively (Figure 2a). Finally,

Table 1. Molecular weights of PCBN, PCBS and PCBSe

\begin{tabular}{|l|c|c|c|}
\hline \multicolumn{1}{|c|}{ Polymer } & $\begin{array}{c}\boldsymbol{M}_{\mathbf{n}} \\
{[\mathbf{D a}]}\end{array}$ & $\begin{array}{c}\boldsymbol{M}_{\mathbf{w}} \\
{[\mathbf{D a}]}\end{array}$ & PDI \\
\hline PCBN & 3339 & 4768 & 1.42 \\
\hline PCBS & 2516 & 3632 & 1.44 \\
\hline PCBSe & 1626 & 2031 & 1.24 \\
\hline
\end{tabular}
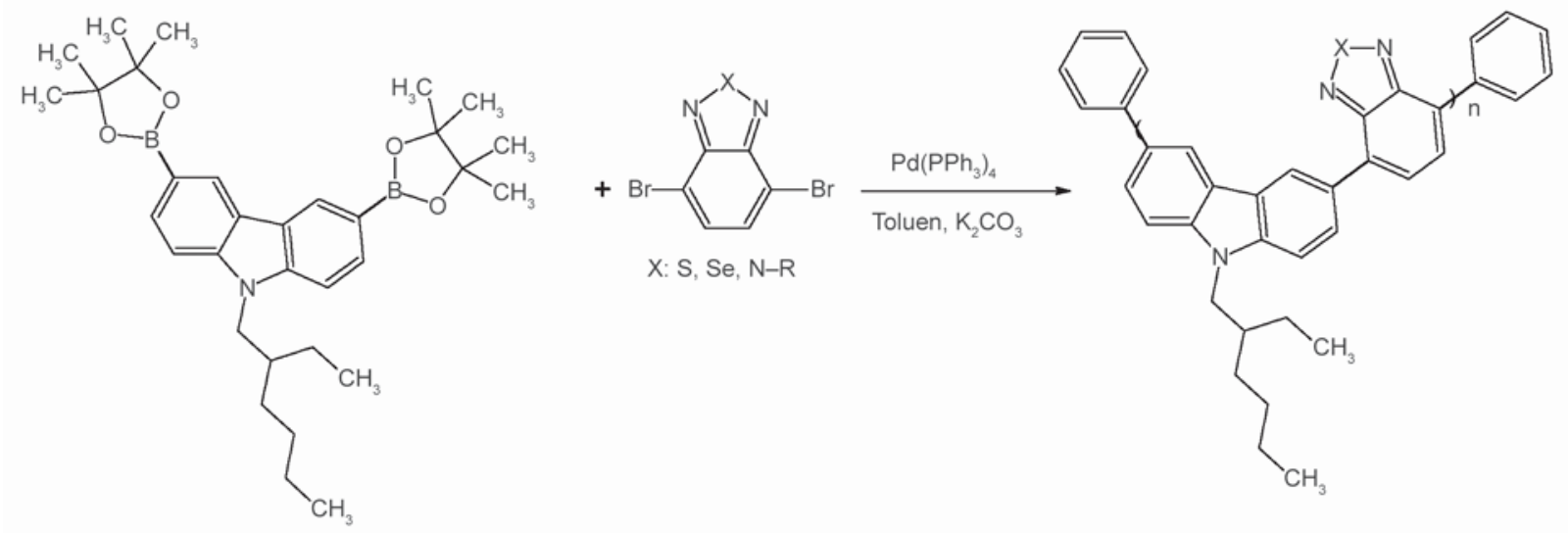

Figure 1. Synthetic route for PCBX polymers 

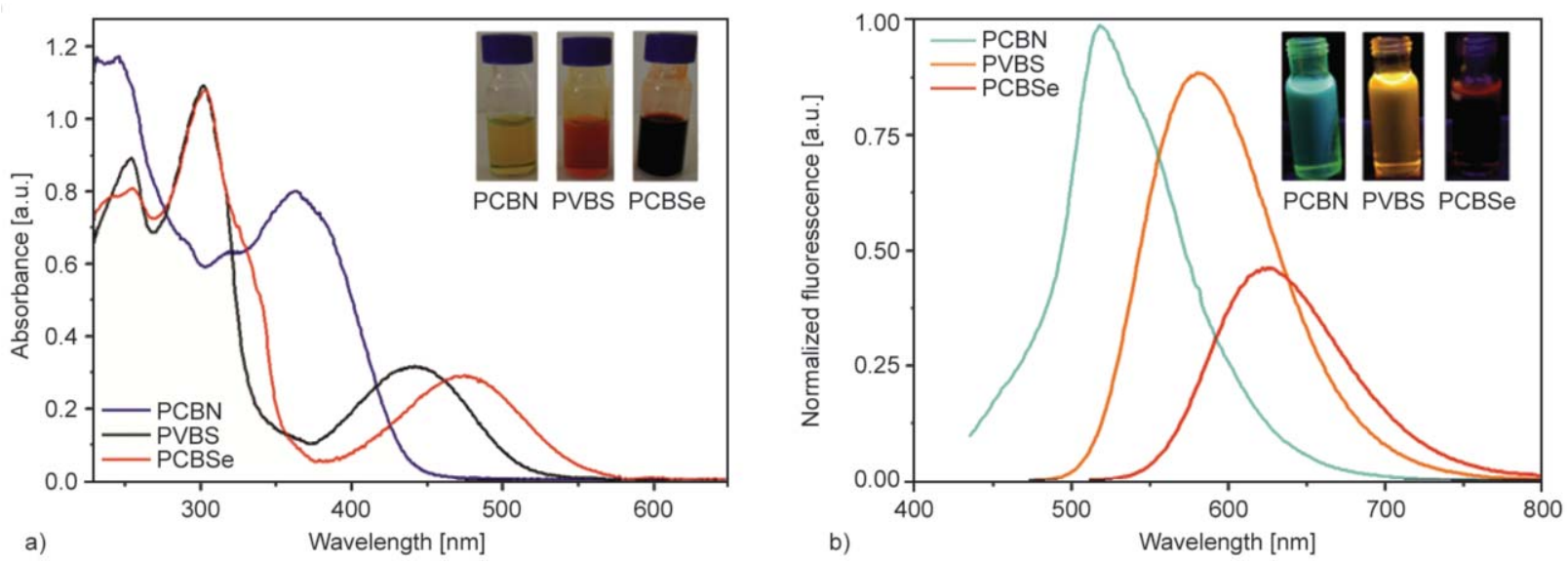

Figure 2. Absorption (a) and fluorescence (b) spectra of $\mathrm{PCBX}$ polymers in $\mathrm{CH}_{2} \mathrm{Cl}_{2}$ solution

the optical band gaps were found to be $2.80 \mathrm{eV}$ for PCBN (at $442 \mathrm{~nm}$ ), $2.42 \mathrm{eV}$ for PCBS (at $513 \mathrm{~nm}$ ) and $2.18 \mathrm{eV}$ for PCBSe (at $569 \mathrm{~nm}$ ) respectively. According to this result, there is about $127 \mathrm{~nm}$ bathochromic shift from PCBN to PCBSe. On the other hand, similar results were observed in the fluorescence measurements. Upon PCBXs excited from absorption maxima of their charge transfer band $\left(\lambda_{\max }=360 \mathrm{~nm}\right.$ for PCBN, $\lambda_{\max }=440 \mathrm{~nm}$ for PCBS, and $\lambda_{\max }=475 \mathrm{~nm}$ for PCBSe) strong emission bands were obtained at 440, 580, and $623 \mathrm{~nm}$ with Stokes' shifts of 157, 140, and $148 \mathrm{~nm}$, respectively (Figure $2 b$ ). The emission colors of the polymer solutions were diverse as cyan, orange and red, respectively. Finally, absorption and fluorescence behavior could be arranged by the substitution of different heteroatoms on the benzazole acceptor moiety to carbazole donor unit.

\subsection{Electrochemical properties of PCBX polymers}

To understand the redox behaviors of PCBX polymers, cyclic voltammetry (CV) technique was used. PCBN, PCBS and PCBSe have a great difference in their redox properties obtained from the $\mathrm{CV}$ voltamograms which are shown in Figure 3. The electrondeficient character of the heteroatom on the benzazole moiety strongly affected the reduction potentials of the polymers in the cathodic regime. PCBN, PCBS and PCBSe polymers have an irreversible reduction peak at $-1.65,-1.50$ and $-1.42 \mathrm{~V}$, respectively. According to these results, changing the electron-deficient unit of the polymer significantly altered the reduction potential of the polymers. Thus, LUMO levels responded differently and consequently PCBSe has a lower band gap value compared with PCBS and PCBN because of the stronger electron-withdrawing character of benzoselenadiazole moiety [26-28].

On the other hand, semi reversible oxidation peaks were found at $E_{\mathrm{p}, \mathrm{a}}^{\mathrm{ox}}=1,35 \mathrm{~V}, E_{\mathrm{p}, \mathrm{c}}^{\mathrm{ox}}=1.01 \mathrm{~V}$ and $E_{\mathrm{p}, 1 / 2}^{\mathrm{ox}}=$ $1.18 \mathrm{~V}$ for PCBN; $E_{\mathrm{p}, \mathrm{a}}^{\mathrm{ox}}=1,26 \mathrm{~V}, E_{\mathrm{p}, \mathrm{c}}^{\mathrm{ox}}=0.98 \mathrm{~V}$ and $E_{\mathrm{p}, 1 / 2}^{\mathrm{ox}}=1.12 \mathrm{~V}$ for PCBS, $E_{\mathrm{p}, \mathrm{a}}^{\mathrm{ox}}=1,58 \mathrm{~V}, E_{\mathrm{p}, \mathrm{c}}^{\mathrm{ox}}=1.05 \mathrm{~V}$ and $E_{\mathrm{p}, 1 / 2}^{\mathrm{ox}}=1.32 \mathrm{~V}$ for PCBSe in the anodic region. According to Table 2, it can be deduced that electrochemical and optical behaviors of the polymers were significantly affected by varying the heteroatom on the acceptor moiety attached to the carbazole-donor main chain.

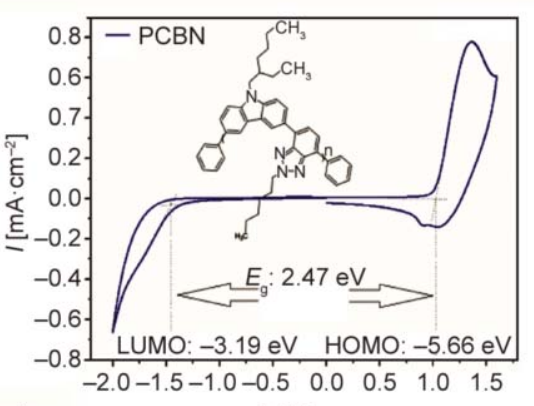

a) $E[\mathrm{~V}]$

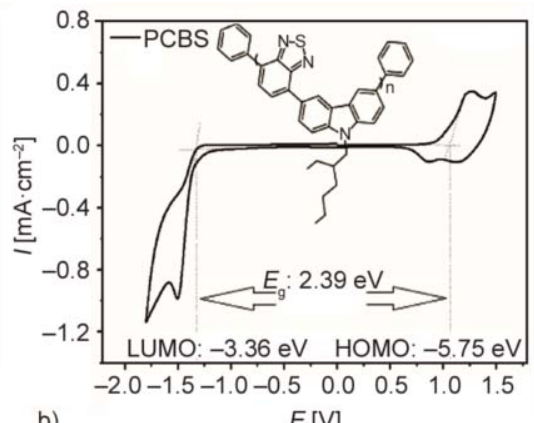

b)

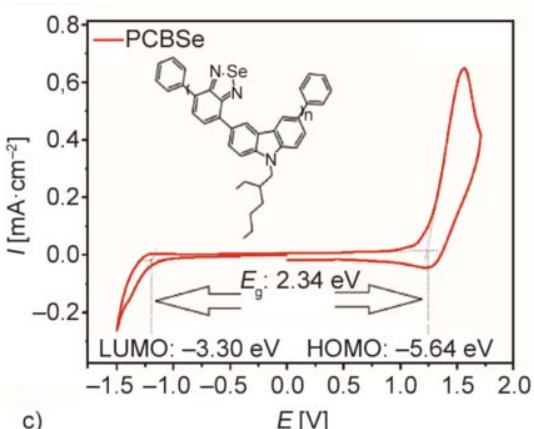

c)

$$
E[\mathrm{~V}]
$$

Figure 3. Redox behavior of PCBN (a) PCBS (b) and PCBSe (c) in $0.1 \mathrm{M} \mathrm{TBAPF} / \mathrm{CH}_{2} \mathrm{Cl}_{2}$ electrolyte solution at scan rate $100 \mathrm{mV} / \mathrm{s}$, vs. Ag wire 
Table 2. HOMO-LUMO, electrochemical and optical band gaps $\left(E_{\mathrm{g}}\right)$ of PCBX polymers

\begin{tabular}{|l|c|c|c|c|}
\hline Polymer & $\begin{array}{c}\text { HOMO } \\
{[\mathbf{e V}]}\end{array}$ & $\begin{array}{c}\text { LUMO } \\
{[\mathbf{e V}]}\end{array}$ & $\begin{array}{c}\text { Optical } \boldsymbol{E}_{\mathbf{g}} \\
{[\mathbf{e V}]}\end{array}$ & $\begin{array}{c}\text { Electrochemical } \boldsymbol{E}_{\mathbf{g}} \\
{[\mathbf{e V}]}\end{array}$ \\
\hline PCBN & -5.66 & -3.19 & 2.80 & 2.47 \\
\hline PCBS & -5.75 & -3.36 & 2.42 & 2.39 \\
\hline PCBSe & -5.64 & -3.30 & 2.18 & 2.34 \\
\hline
\end{tabular}

\subsection{Surface morphologies}

Morphology of PCBN, PCBS and PCBSe film surfaces was examined by atomic force microscopy (AFM) (Figure 4). Polymer solutions were obtained from $20 \mathrm{mg} / \mathrm{mL}$ of $\mathrm{PCBX}$ in $\mathrm{CHCl}_{3}$. $\mathrm{PCBX}$ polymer films were prepared by using spin-casting method on ITO substrates at $2000 \mathrm{rpm}$ for $60 \mathrm{~s}$ from the polymer solutions. While the thickness of the films were calculated as 96, 168 and $190 \mathrm{~nm}$, for PCBN, PCBS and PCBSe respectively, the RMS (root mean sur-

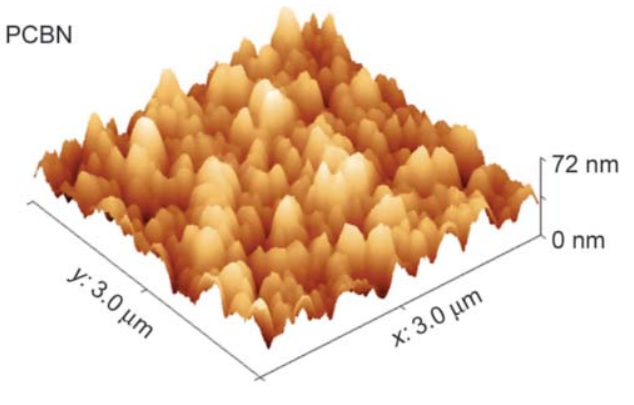

a)

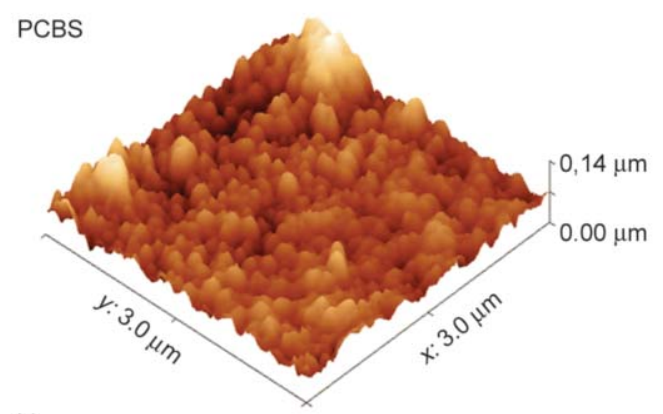

b)

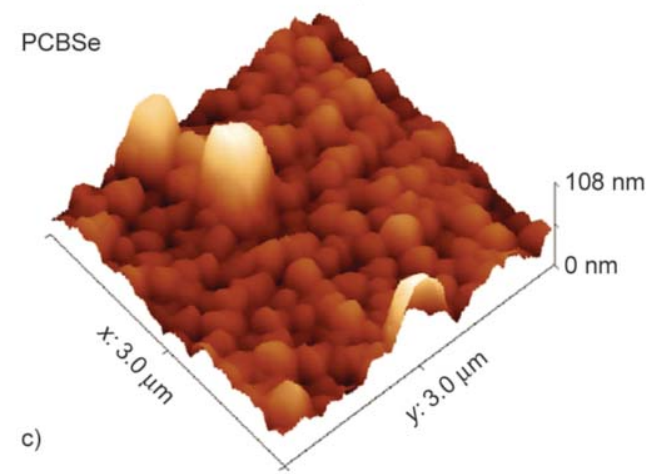

face) roughness of polymers are found to be 10.38 , 18.87 and $25.45 \mathrm{~nm}$. The AFM image of the PCBS and PCBSe exhibit conglomerate non-uniform structure and the roughness of these polymer films are high. Besides, PCBN has a longer side alkyl chain on the benzotriazole acceptor moiety. Because of this, solvation is promoted by increasing the length of the alkyl chain. As a result of increasing the solubility and also expansion of $\pi$ conjugation along the polymer backbone, a uniform surface could be obtained. Consequently, better polymer thin films could be obtained by decreasing the roughness $[29,30]$. As known in the literature [31-33] during electrochromic switching, the electrolyte ions are injected/ejected to the polymer film surface. Because of the feature, the electrochromic performance of the PCBX polymer was affected by the polymer film surface roughness.
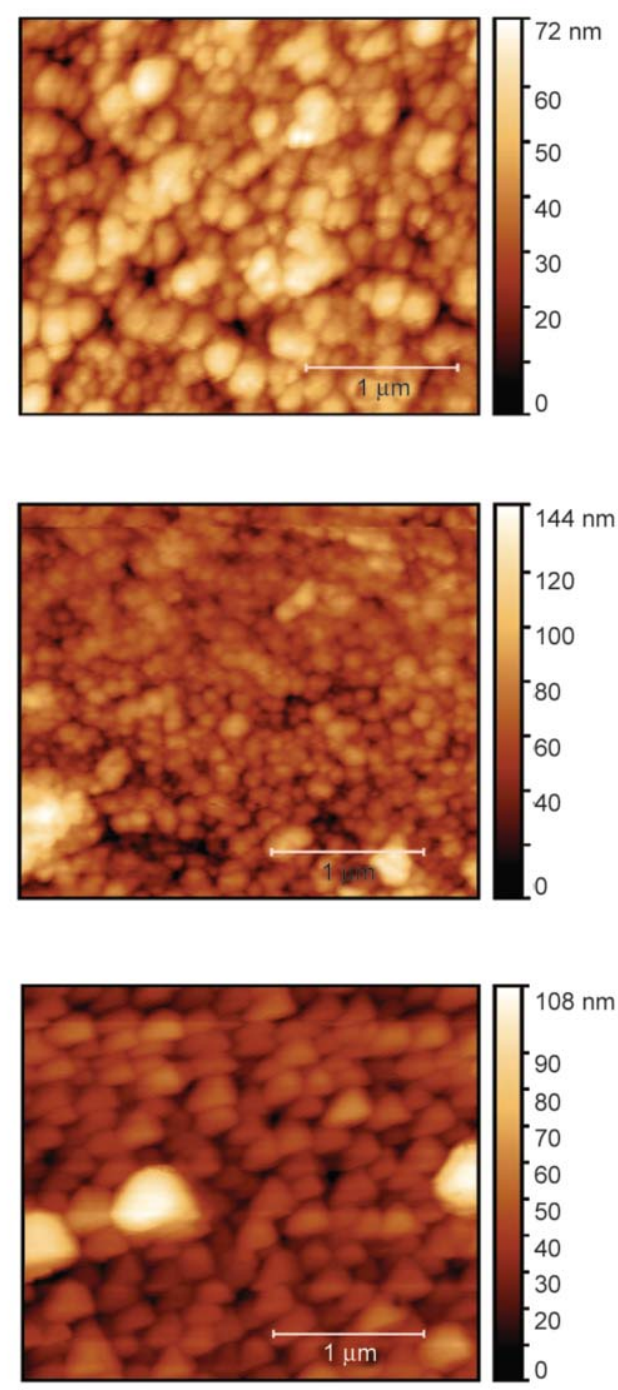

Figure 4. AFM image of PCBN (a), PCBS (b) and PCBSe (c) onto ITO/glass surface 


\subsection{Spectroelectrochemical properties of PCBX polymers}

Spectroelectrochemical investigation of PCBN, PCBS and PCBSe films was carried out via Diode-array UV-Vis spectrophotometer. While oxidation of PCBN film $(0-1.2 \mathrm{~V})$, an absorption band at $360 \mathrm{~nm}$ corresponds to valence band-conduction band $\left(\pi \rightarrow \pi^{*}\right.$ transition) started to decrease and another band intensified at $550 \mathrm{~nm}$. This new absorption band pointed out the formation of polaron on the carbazole based polymer chain and thus light yellow neutral state color of the film (L: 78.7; a: -13.5; b: 47.8) converted to green (L: 71.5; a: -27.5 ; b: 56.9). Additionally, upon applied higher potentials (1.2-1.8 V), another new band was observed in the near-IR region (at $860 \mathrm{~nm}$ ) as a result of the formation of a bipolaron. Consequently, the color of the $\mathbf{P C B N}$ polymer film turned into red (L: 39.01; a: 4.98; b: 4.54) at fully oxidized state (Figure 5).

Anodic scan of PCBS (0 to $1.8 \mathrm{~V}$ ) (Figure 6), the charge transfer band at $455 \mathrm{~nm}$ decreased, and two new absorption bands were started to form at $600 \mathrm{~nm}$ $(0-1.4 \mathrm{~V})$ and $825 \mathrm{~nm}(1.4-1.8 \mathrm{~V})$ (Figure 5). Moreover, formation of polaron and bipolaron on the PCBS polymer backbone was verified by the intensification of the broad band in the visible and near-IR regime (Figure 5). While the orange color of the film at neutral state (L: 69.57; a: 5.66; b: 56.67) changed to blue (L: 24.9; a: 3.6; b: -28.7) and then black (L: 39.08; a: $-0.4 ;$ b: -1.25$)$ upon the applied positive potential (Figure 6).

Further, red color PCBSe polymer film (L: 42.6; a: 28.6; b: 32.6) was exhibited a maximum absorption band at $475 \mathrm{~nm}$ ( $\lambda_{\max }$, the charge transfer band) at the neutral state. During to anodic scan (Figure 7), in-

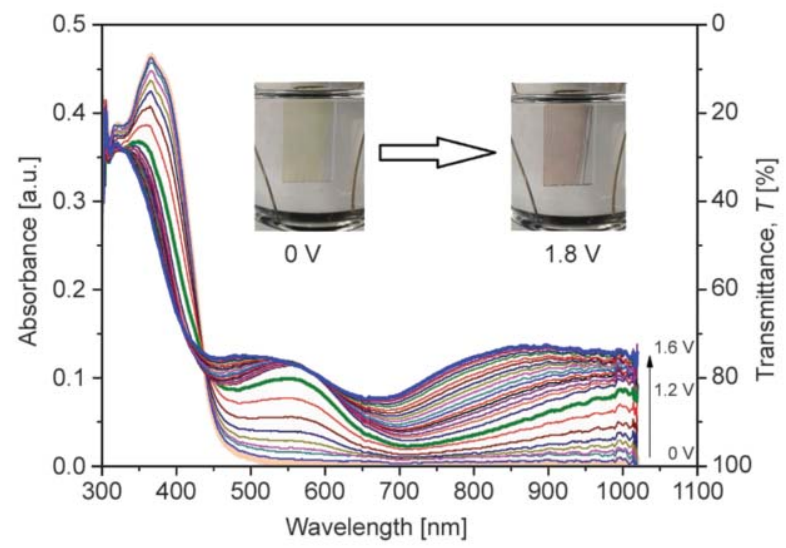

Figure 5. Color changes and spectroelectrochemistry of PCBN film on ITO in the anodic region

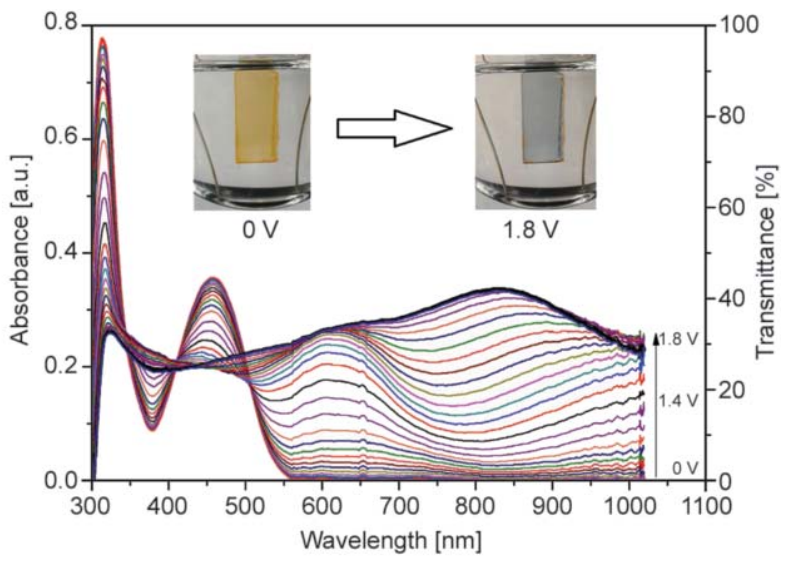

Figure 6. Color changes and spectroelectrochemistry of PCBS film on ITO in the anodic region

tensity of $\pi \rightarrow \pi^{*}$ transition and charge transfer bands were decreased. On the other hand, new absorption bands at about $650 \mathrm{~nm}(0-1.4 \mathrm{~V})$ and $800 \mathrm{~nm}(1.4$ $1.8 \mathrm{~V})$ started to be intensified depending on the formation of polarons and bipolarons, respectively (Figure 7). Hence, above $700 \mathrm{~nm}$ (the Near-IR region) was intensely absorbed by the PCBSe polymer film at fully oxidized state. According to these results, the red polymer film converted to oily green (L: 34.5 ; a: -11.7 ; b: 16.5), and dark blue (L: 29.6; a: -2.98 ; b: -11.7 ), respectively (Figure 7).

Kinetic performance of PCBX polymers was carried out by the square-wave voltammetry which observes the difference of transmittance at the point of absorption maxima against to time while applying voltage between redox states of polymers with a residence time of $10 \mathrm{~s}$ (Figure 7). The percentage transmittance change $(\Delta T \%)$ of PCBX polymers was investigated between $0-1.8 \mathrm{~V}$ with switching time of $10 \mathrm{~s}$. As a result of these measurements, $\triangle T \%$ was found to be $21 \%$ for PCBN at $860 \mathrm{~nm}, 45 \%$ for PCBS at $825 \mathrm{~nm}$

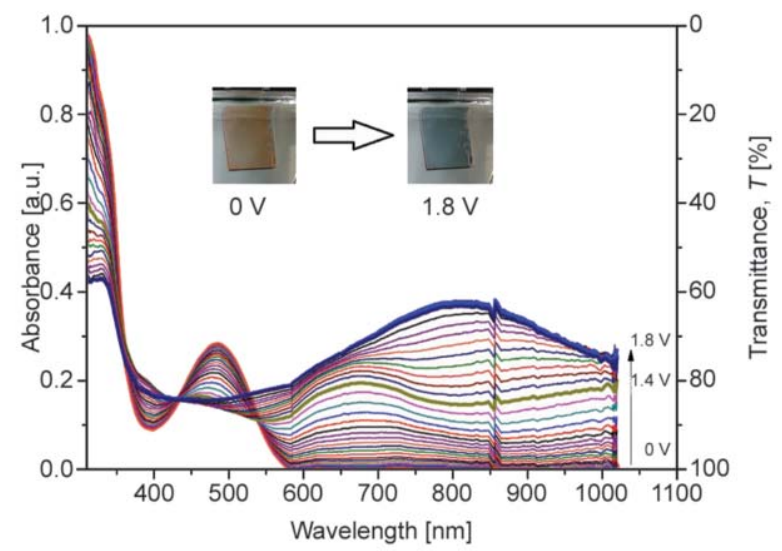

Figure 7. Color changes and spectroelectrochemistry of PCBSe film on ITO in the anodic region 

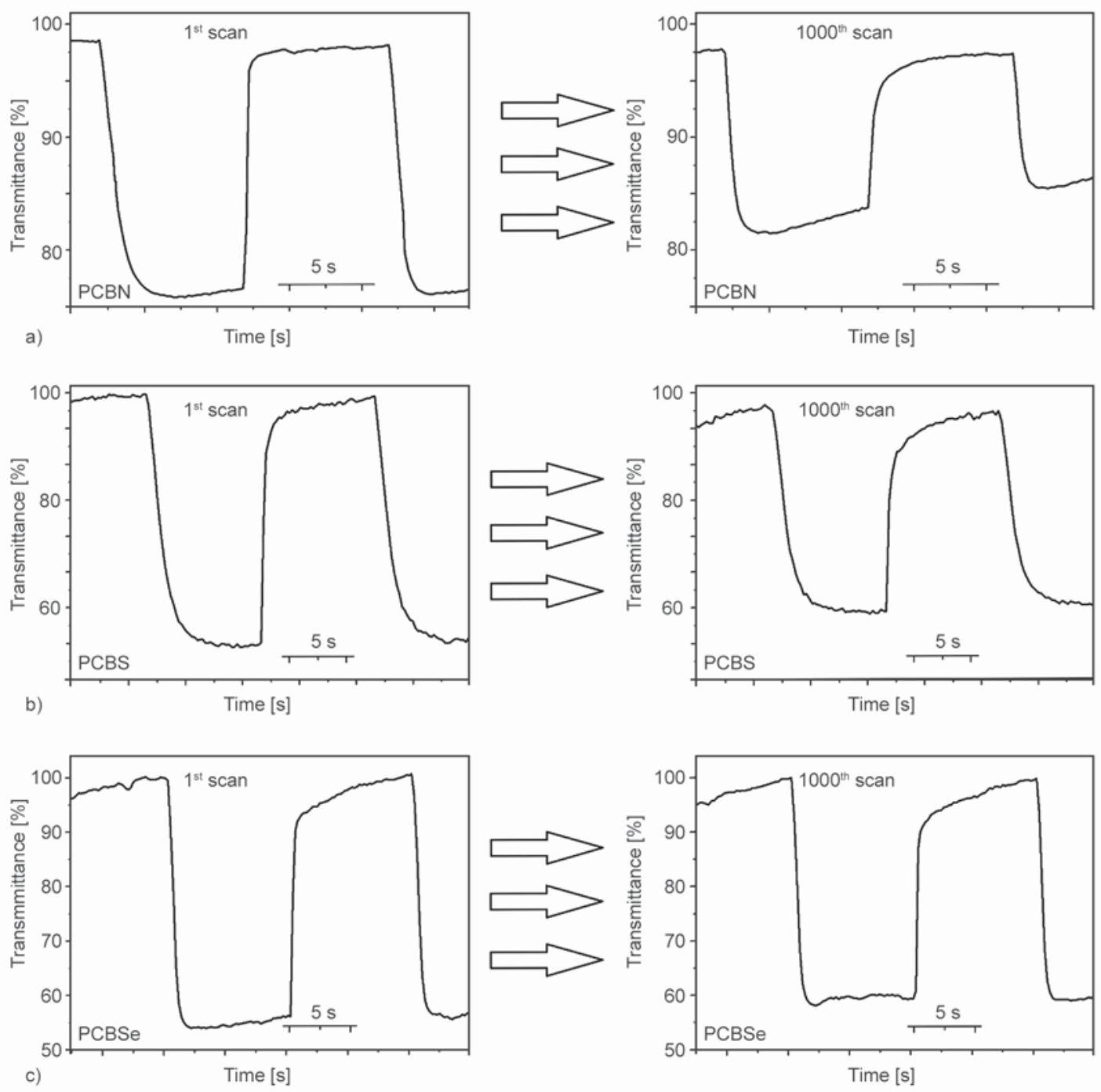

Figure 8. Stability test of polymers. [Optical difference watched at $860 \mathrm{~nm}$ for PCBN (a), $825 \mathrm{~nm}$ for PCBS (b) and $800 \mathrm{~nm}$ for PCBSe between 0 and $1.8 \mathrm{~V}(\mathrm{c})]$

and $41 \%$ for PCBN at $800 \mathrm{~nm}$ respectively (Figure 8).

Optical activity is one of the most significant parameter to determine the electrochromic performance of the polymer films [34]. While PCBN has $62 \%$ of the optical activity, PCBS and PCBSe have $84 \%$ and $86 \%$ of the optical activity after 1000 cycles, respectively. The reduction and oxidation response times were also determined. The values were found to be 4.8 and $1.2 \mathrm{~s}$ for PCBN, 2.4 and $6.1 \mathrm{~s}$ for PCBS, and 1.8 and $2.4 \mathrm{~s}$ for PCBSe respectively.

Another important parameter is coloration efficiency (CE) for the electrochromic applications. CE was determined via the equation: $\mathrm{CE}=\Delta \mathrm{OD} / Q_{\mathrm{d}}$ and $\Delta \mathrm{OD}=$ $\log \left(T_{\text {colored }} / T_{\text {bleached }}\right)$ [where $T_{\text {bleached }}$ is transmittance at neutral state, $T_{\text {colored }}$ is transmittance at oxidized state and $Q_{\mathrm{d}}$ is Injected/ejected charge between redox states] [25]. According to this equation, $C E$ values of PCBN, PCBS and PCBSe were determined as 93, 178 and $154 \mathrm{~cm}^{2 .}{ }^{\circ} \mathrm{C}^{-1}$ respectively. As it can be clearly observed, CE values of PCBS and PCBSe are approximately two times greater than that of PCBN. Considering all data, electrochromic performance of the polymers was significantly affected by the type of heteroatom on the benzoazole acceptor moiety. Finally, PCBN, PCBS and PCBSe polymer films exhibited multi-electrochromic behavior, reasonable response time and optical contrast. Furthermore, PCBS has a broad absorption band in both the visible and near-IR regime at its oxidized state. Consequently, it could be a good candidate to use a visible and near-IR filter in various applications. 


\section{Conclusions}

In this work, a series of carbazole based electrochromic polymers with benzazole moiety as electron-acceptor were synthesized and characterized. Besides, the heteroatom variation effects on the analogous electrochromic polymers were also investigated. The polymer thin films of PCBX were obtaining by using spin-casting metod. They have several colors presented for the neutral and polaronic species, owing to multiple redox behavior of carbazole moiety at their oxidized state. The neutral state color of PCBX polymers were yellow, orange and red, respectively. On the other hand, the color of the films converted to red, black and dark blue at fully oxidized state, respectively. In conclusion, electrochromic polymers PCBN, PCBS and PCBSe exhibit medium band gaps $(2.47,2.39$ and $2.34 \mathrm{eV})$ and reasonable electrochromic performance (optical activity, coloration efficiency and oxidation/reduction times).

\section{Acknowledgements}

The authors would like thank Çanakkale Onsekiz Mart University for financial support (Project Number: 2015/56).

\section{References}

[1] Shirota Y.: Organic materials for electronic and optoelectronic devices. Journal of Materials Chemistry, 10, $1-25(2000)$.

DOI: $10.1039 / \mathrm{a} 908130 \mathrm{e}$

[2] Niklasson G. A., Granqvist C. G.: Electrochromics for smart windows: Thin films of tungsten oxide and nickel oxide, and devices based on these. Journal of Materials Chemistry, 17, 127-156 (2007).

DOI: $10.1039 / \mathrm{b} 612174 \mathrm{~h}$

[3] Granqvist C. G., Azens A., Hjelm A., Kullman L., Niklasson G. A., Rönnow D., Mattsson M. S., Veszelei M., Vaivars G.: Recent advances in electrochromics for smart windows applications. Solar Energy, 63, 199-216 (1998).

DOI: 10.1016/S0038-092X(98)00074-7

[4] Mortimer R. J.: Electrochromic materials. Chemical Society Reviews, 26, 147-156 (1997). DOI: $10.1039 / \mathrm{cs} 9972600147$

[5] Rosseinsky D. R., Mortimer R. J.: Electrochromic systems and the prospects for devices. Advanced Materials, 13, 783-793 (2001).

DOI: 10.1002/1521-4095(200106)13:11<783::AIDADMA783>3.0.CO;2-D
[6] Chandrasekhar P., Zay B., Birur G. C., Rawal S., Pierson E. A., Kauder L., Swanson T.: Large, switchable electrochromism in the visible through far-infrared in conducting polymer devices. Advanced Functional Materials, 12, 95-103 (2002).

DOI: $10.1002 / 1616-3028(20020201) 12: 2<95:: A I D-$ ADFM95>3.3.CO;2-E

[7] Beaupré S., Breton A-C., Dumas J., Leclerc M.: Multicolored electrochromic cells based on poly(2,7-carbazole) derivatives for adaptive camouflage. Chemistry of Materials, 21, 1504-1513 (2009).

DOI: $10.1021 / \mathrm{cm} 802941 \mathrm{e}$

[8] Zhang Z-B., Fujiki M., Tang H-Z., Motonaga M., Torimitsu K.: The first high molecular weight poly $(\mathrm{N}$ alkyl-3,6-carbazole)s. Macromolecules, 35, 1988-1990 (2002).

DOI: $10.1021 / \mathrm{ma} 011911 \mathrm{~b}$

[9] Blouin N., Michaud A., Gendron D., Wakim S., Blair E., Neagu-Plesu R., Belletête M., Durocher G., Tao Y., Leclerc M.: Toward a rational design of poly(2,7-carbazole) derivatives for solar cells. Journal of the American Chemical Society, 130, 732-742 (2008). DOI: $10.1021 / \mathrm{ja} 0771989$

[10] Watanabe T., Ueda S., Inuki S., Oishi S., Fujii N., Ohno H.: One-pot synthesis of carbazoles by palladium-catalyzed $N$-arylation and oxidative coupling. Chemical Communications, 43, 4516-4518 (2007).

DOI: 10.1039/b707899d

[11] Thomas K. R. J., Lin J. T., Tao Y-T., Ko C-W.: Lightemitting carbazole derivatives: Potential electroluminescent materials. Journal of the American Chemical Society, 123, 9404-9411 (2001).

DOI: $10.1021 / \mathrm{ja} 010819 \mathrm{~s}$

[12] Pomerantz Z., Zaban A., Ghosh S., Lellouche J-P., Garcia-Belmonte G., Bisquert J.: Capacitance, spectroelectrochemistry and conductivity of polarons and bipolarons in a polydicarbazole based conducting polymer. Journal of Electroanalytical Chemistry, 614, 49-60 (2008).

DOI: 10.1016/j.jelechem.2007.11.005

[13] Liou G-S., Hsiao S-H., Huang N-K., Yang Y-L.: Synthesis, photophysical, and electrochromic characterization of wholly aromatic polyamide blue-light-emitting materials. Macromolecules, 39, 5337-5346 (2006). DOI: $10.1021 / \mathrm{ma} 0608469$

[14] Akcelrud L.: Electroluminescent polymers. Progress in Polymer Science, 28, 875-962 (2003). DOI: $10.1016 / \mathrm{S} 0079-6700(02) 00140-5$

[15] Getautis V., Daskeviciene M., Malinauskas T., Gaidelis V., Jankauskas V., Tokarski Z.: Cross-linkable hydrazone-containing molecular glasses for electrophotography. Synthetic Metals, 155, 599-605 (2005). DOI: $10.1016 / j . s y n t h m e t .2005 .09 .039$ 
[16] Brunner K., van Dijken A., Börner H., Bastiaansen J. J. A. M., Kiggen N. M. M., Langeveld B. M. W.: Carbazole compounds as host materials for triplet emitters in organic light-emitting diodes: Tuning the HOMO level without influencing the triplet energy in small molecules. Journal of the American Chemical Society, 126, 6035-6042 (2004).

DOI: $10.1021 / \mathrm{ja} 049883 \mathrm{a}$

[17] Tsai M-H., Lin H-W., Su H-C., Ke T-H., Wu C-C., Fang F-C., Liao Y-L., Wong K-T., Wu C-I.: Highly efficient organic blue electrophosphorescent devices based on 3,6-bis(triphenylsilyl)carbazole as the host material. Advanced Materials, 18, 1216-1220 (2006). DOI: $10.1002 / \mathrm{adma} .200502283$

[18] Cirpan A., Argun A. A., Grenier C. R. G., Reeves B. D., Reynolds J. R.: Electrochromic devices based on soluble and processable dioxythiophene polymers. Journal of Materials Chemistry, 13, 2422-2428 (2003). DOI: 10.1039/b306365h

[19] Witker D., Reynolds J. R.: Soluble variable color carbazole-containing electrochromic polymers. Macromolecules, 38, 7636-7644 (2005).

DOI: $10.1021 / \mathrm{ma} 050805 \mathrm{x}$

[20] Schwendeman I., Hickman R., Sönmez G., Schottland P., Zong K., Welsh D., Reynolds J. R.: Enhanced contrast dual polymer electrochromic devices. Chemistry of Materials, 14, 3118-3122 (2002).

DOI: $10.1021 / \mathrm{cm} 020050 \mathrm{y}$

[21] Wang H-M., Hsiao S-H., Liou G-S., Sun C-H.: Synthesis, photoluminescence, and electrochromism of polyamides containing (3,6-di-tert-butylcarbazol-9-yl)triphenylamine units. Journal of Polymer Science Part A: Polymer Chemistry, 48, 4775-4789 (2010).

DOI: $10.1002 /$ pola.24269

[22] Koyuncu F. B., Koyuncu S., Ozdemir E.: A novel donoracceptor polymeric electrochromic material containing carbazole and 1,8-naphtalimide as subunit. Electrochimica Acta, 55, 4935-4941 (2010).

DOI: $10.1016 /$ j.electacta.2010.03.094

[23] Icli M., Pamuk M., Algi F., Önal A. M., Cihaner A.: Donor-acceptor polymer electrochromes with tunable colors and performance. Chemistry of Materials, 22, 4034-4044 (2010).

DOI: $10.1021 / \mathrm{cm} 100805 \mathrm{~g}$

[24] Patil A. O., Heeger A. J., Wudl F.: Optical properties of conducting polymers. Chemical Reviews, 88, 183-200 (1988).

DOI: $10.1021 / \mathrm{cr} 00083 \mathrm{a} 009$

[25] Thompson B. C., Schottland P., Sonmez G., Reynolds J. R.: In situ colorimetric analysis of electrochromic polymer films and devices. Synthetic Metals, 119, 333334 (2001).

DOI: $\underline{10.1016 / \mathrm{S} 0379-6779(00) 00863-8}$
[26] Das S., Pati P. B., Zade S. S.: Cyclopenta[c]thiophenebased D-A conjugated copolymers: Effect of heteroatoms ( $\mathrm{S}, \mathrm{Se}$, and $\mathrm{N}$ ) of benzazole acceptors on the properties of polymers. Macromolecules, 45, 5410 5417 (2012).

DOI: $10.1021 / \mathrm{ma3} 006697$

[27] Shen P., Bin H., Zhang Y., Li Y.: Synthesis and optoelectronic properties of new D-A copolymers based on fluorinated benzothiadiazole and benzoselenadiazole. Polymer Chemistry, 5, 567-577 (2014).

DOI: 10.1039/C3PY00968H

[28] Baran D., Oktem G., Celebi S., Toppare L.: Neutralstate green conjugated polymers from pyrrole bis-substituted benzothiadiazole and benzoselenadiazole for electrochromic devices. Macromolecular Chemistry and Physics, 212, 799-805 (2011).

DOI: $10.1002 / \mathrm{macp} .201000744$

[29] Zhang Q., Cirpan A., Russell T. P., Emrick T.: Donoracceptor poly(thiophene-block-perylene diimide) copolymers: Synthesis and solar cell fabrication. Macromolecules, 42, 1079-1082 (2009). DOI: $10.1021 / \mathrm{ma} 801504 \mathrm{e}$

[30] Li Z., Zhang Y., Tsang S-W., Du J., Zhou J., Tao Y., Ding J.: Alkyl side chain impact on the charge transport and photovoltaic properties of benzodithiophene and diketopyrrolopyrrole-based copolymers. Journal of Physical Chemistry C, 115, 18002-18009 (2011). DOI: 10.1021/jp202996p

[31] Poverenov E., Li M., Bitler A., Bendikov M.: Major effect of electropolymerization solvent on morphology and electrochromic properties of PEDOT films. Chemistry of Materials, 22, 4019-4025 (2010).

DOI: $10.1021 / \mathrm{cm} 100561 \mathrm{~d}$

[32] Mortimer R. J., Graham K. R., Grenier C. R. G., Reynolds J. R.: Influence of the film thickness and morphology on the colorimetric properties of spray-coated electrochromic disubstituted 3,4-propylenedioxythiophene polymers. ACS Applied Materials and Interfaces, 10, 2269-2276 (2009).

DOI: $10.1021 / \mathrm{am} 900431 \mathrm{z}$

[33] Neo W. T., Shi Z., Cho C. M., Chua S-J., Xu J.: Effects of chemical composition, film thickness, and morphology on the electrochromic properties of donor-acceptor conjugated copolymers based on diketopyrrolopyrrole. ChemPlusChem, 80, 1298-1305 (2015). DOI: $10.1002 / \mathrm{cplu} .201500182$

[34] Cihaner A., Algi F.: A processable rainbow mimic fluorescent polymer and its unprecedented coloration efficiency in electrochromic device. Electrochimica Acta, 53, 2574-2578 (2008). DOI: $10.1016 /$ j.electacta.2007.10.030 